\title{
Güneş pilleri için ZnO'nun yapısal ve elektronik özelliklerinin incelenmesi: Ab-initio çalışması
}

\author{
Cihan KÜRKÇÜ ${ }^{1, ~ *, ~ Z i y a ~ M E R D A N ~}{ }^{2}$ \\ ${ }^{1}$ Ahi Evran Üniversitesi, Teknik Bilimler Meslek Yüksekokulu, Elektronik ve Otomasyon Bölümü, Kırşehir \\ ${ }^{2}$ Gazi Üniversitesi, Fen Fakültesi, Fizik Bölümü, Ankara \\ Geliş Tarihi (Recived Date): 11.01.2018 \\ Kabul Tarihi (Accepted Date): 13.04.2018
}

\section{Özet}

$\mathrm{ZnO}$ bileşiğinin kristal yapısı yoğunluk fonksiyonel teorisi (DFT) ile genelleştirilmiş gradyant yaklaşımı (GGA) kullanılarak yüksek hidrostatik basınç altında 100 GPa'ya kadar çalışıldı. Çevre koşullarında ZnO, uzay grubu P6зmc olan wurtzite (B4) tipi yapıda kristalleşir. Bu yapı üzerine artan basınç uygulandığında, ZnO'nun B4 yapısı uzay grubu $\mathrm{Fm} \overline{3}$ m olan $\mathrm{NaCl}$ (B1) tipi yapıya dönüşmüştür. Bu çalışmada elde edilen faz geçişinin deneysel sonuçlarla uyumunu araştırmak için toplam enerji ve entalpi hesaplamaları yapıldı. Bu hesaplamalar sonucu faz değişiminin 9 GPa civarında gerçekleştiği sonucuna varıldı. Bu sonucun literatür ile uyum içinde olduğu görüldü. Ayrıca ZnO'nun elektronik özellikleri de incelendi. B4 ve B1 yapıları için band aralıkları sirası ile $0.7 \mathrm{eV}$ ve $1.95 \mathrm{eV}$ olarak elde edildi.

Anahtar Kelimeler: Yapısal faz geçişi, DFT, ab-initio moleküler dinamik, güneş pili.

\section{Investigation of structural and electronic properties of $\mathrm{ZnO}$ for solar cells: An ab-initio study}

\begin{abstract}
The crystal structure of the $\mathrm{ZnO}$ compound was studied up to $100 \mathrm{GPa}$ under high hydrostatic pressure using the density functional theory (DFT) with the generalized gradient approximation (GGA). Under ambient conditions, ZnO crystallizes in wurtzite (B4) type structure with space group P63mc. When increased pressure is applied to this structure, the $\mathrm{B} 4$ structure of $\mathrm{ZnO}$ is transformed into the $\mathrm{NaCl}$ (B1) type structure, which is the space group $F m \overline{3} m$. Total energy and enthalpy calculations were carried

* Cihan KÜRKÇÜ, ckurkcu @ ahievran.edu.tr, https://orcid.org/0000-0003-3597-1950
Ziya MERDAN, ziyamerdan@ @gazi.edu.tr, https://orcid.org/0000-0001-6255-4242
\end{abstract}


out to investigate the phase transition obtained in this study with experimental results. These calculations are the result of a phase change of around 9 GPa. This result was found to be in accordance with the literature. The electronic properties of $\mathrm{ZnO}$ have also been studied. B4 and B1 band gaps were $0.7 \mathrm{eV}$ and $1.95 \mathrm{eV}$, respectively.

Keywords: Structural phase transition, DFT, ab-initio molecular dynamics, solar cell.

\section{Giriş}

Çeşitli alanlardaki teknolojik öneminden dolayı (fotovoltaik, piezoelektrik yüzey akustik dalga cihazları, varistör, optik dalga kılavuzları, gaz sensörleri, seramik vb.) ZnO'nun özellikleri, son yıllarda, birçok deneysel ve teorik çalışmaya konu olmuştur [1-13]. Fotovoltaiklerde, $\mathrm{ZnO}$ filmleri, bakır indiyum-diselenid [14] veya amorf silikondan [15] oluşan ince film güneş pillerinde n-tipi iletken cam olarak kullanılırlar. Yeni nesil güneş pilleri için düşük maliyetli bir materyaldir. Aynı zamanda ZnO'nun yüksek basınç davranışı teorik olarak da ilgi çekmeyi başarmıştır [8, 16-18]. Temel malzeme fiziğinin yanı sıra Jeofizik alanında da ZnO'nun yüksek basınç davranışı üzerine devam eden bir ilgi vardır. [2]

ZnO'da basınca bağlı faz geçişi deneysel ve teorik olarak incelenmiştir. Deneysel çalışmalar, ZnO'nun B4 fazının yaklaşık 10 GPa'da B1 fazına dönüştüğünü ortaya koymuştur [19] ve daha sonra bu dönüşüm Jamieson [20] ve Yu ve ark. [21] tarafından doğrulanmıştır. Desgreniers, B4 $\rightarrow$ B1 geçişi için geçiş basıncının $(\mathrm{Pt}) 9.1 \pm 0.2 \mathrm{GPa}$ olduğunu ve hacimde \% 16.7'lik bir çöküşü̈n olduğunu bildirdi [3]. Enerji Dağılımlı X1şınları Kırınımı (EDX) çalışmaları ise $\mathrm{B} 4 \rightarrow \mathrm{B} 1$ geçişinin oda sıcaklığında yaklaşık $9.8 \mathrm{GPa}$ da meydana geldiğini göstermiştir $[22,23]$. Buna ek olarak, ZnO'nun özellikleri son yıllarda çeşitli teorik çalışmalara konu olmuştur [1, 17, 18, 24, 25]. Önceden yapılan yüksek basınçlı yapısal hesaplamalar çoğunlukla B4'ten B1'e faz dönüşümüne odaklanmıştır. Gaussian-tipi orbitallerin doğrusal kombinasyonu (LCGTO) HartreeFock (HF) yöntemi, 8.57 GPa olarak geçiş basıncını bildirmiştir [17]. ZnO'nun elastik ve yapısal özellikleri tam potansiyel Lineer Muffin-tin Orbital metodu (FP-LAPW) ile araştırılmıştır [24]. Son zamanlarda, B4'ten B1 ve B3 fazlarına geçişin yanı sıra ZnO'nun üç fazdaki (B4, B1, B3) yapısal parametreleri, hem yerel yoğunluk yaklaşımı (LDA) hem de genelleştirilmiş gradyant yaklaşımı (GGA) ile yoğunluk fonksiyonel teori (DFT) çerçevesinde sunuldu [25].Ayrıca ZnO'nun düşük ve yüksek basınç fazları için elektronik özellikleri incelendi ve her iki fazının da yarıiletken özellik gösterdiği bulundu.

Bu makalenin amacı, Siesta paket programını kullanarak ZnO'nun yapısal ve elektronik özelliklerinin diğer teorik ve deneysel çalışmalar ile karşılaştırmalı ve literatür eksiğini tamamlayıcı bir çalışma sağlamasıdır.

\section{Yöntem}

ZnO'nun wurtzite tipi yapısının yapısal ve elektronik özellikleri yoğunluk fonksiyonel teori çerçevesinde ab-initio metodu kullanılarak incelendi. Çalışmada ab-initio kod olarak SİESTA [26] paket programı kullanıldı. Yaklaşım olarak GGA uygulandı ve 
Perdew-Burke-Ernzerhof (PBE) [27] değiş tokuş-korelasyon fonksiyonu parametreleri "double $\zeta(\mathrm{DZ})$ basis set" ile hesaba katıldı.

Elektronik bant yapıları, toplam durum yoğunluk ve kısmi durum yoğunluğu hesaplamaları için Troullier-Martins'in [28] norm-koruyucu pseudo-potansiyeli kullanıldı. Çalışmada cut off enerjisi yapılan optimizasyonlar sonucunda 300 Ryd olarak yeterli görüldü. Enerji hacim arasındaki ilişkiyi hesaplayabilmek için B4 ve B1 yapıları için kristal yapıların birim hücrelerinden faydalanıldı. Brillouin bölgesi entegrasyonu için sırası ile uzay gurubları $\mathrm{P} 63 \mathrm{mc}$ ve $\mathrm{Fm} \overline{3} \mathrm{~m}$ için $8 \times 8 \times 6$ ve $8 \times 8 \times 8$ Monkhorst-Pack (MP) [29] mesh kullanıldı. Simulasyon hücreleri $2 \times 3 \times 3$ supercell kullanılarak periyodik bağ koşullarında 72 atomdan oluşturuldu. Basınç, ParrinelloRahman [30] tekniği ile sisteme uygulanarak kademeli olarak 10 GPa'lık artışlarla artırıldı. Her bir simülasyon adımını analiz edebilmek için KPLOT [31] programı ve RGS [32] algoritması kullanıldı. Bunlar, analiz edilen bir yapının uzay grubu, atom pozisyonları ve örgü parametreleri hakkında detaylı bilgi vermektedir. Her bir moleküler dinamik (MD) zaman adımı için 1.0 femtosaniye kullanıldı. Ayrıca faz dönüşümleri ve mekanizmalarını görselleştirmek için Crystalmaker programından faydalanıld1.

\section{Bulgular}

KPLOT programını kullanarak her bir uygulanan basınç değerinde ZnO'nun yapısı analiz edildi ve hekzagonal yapısının $30 \mathrm{GPa}$ 'ya kadar korunduğu gözlemlendi. 30 GPa'da yapılan analiz sonucunda hekzagonal B4 tipi yapıdan kübik B1 tipi yapıya bir faz dönüşümünün olduğunu gözlemledik. Bu dönüşüm sonunda elde ettiğimiz kararlı fazlar Şekil 1'de gösterildi ve bu yapılara ait geçiş basınç değerleri, örgü parametreleri, hacim değerleri, bulk modülü ve bulk modülün türevi değerleri diğer teorik ve deneysel çalışmalarla karşıllaştırılmalı olarak Tablo 1'de verildi.

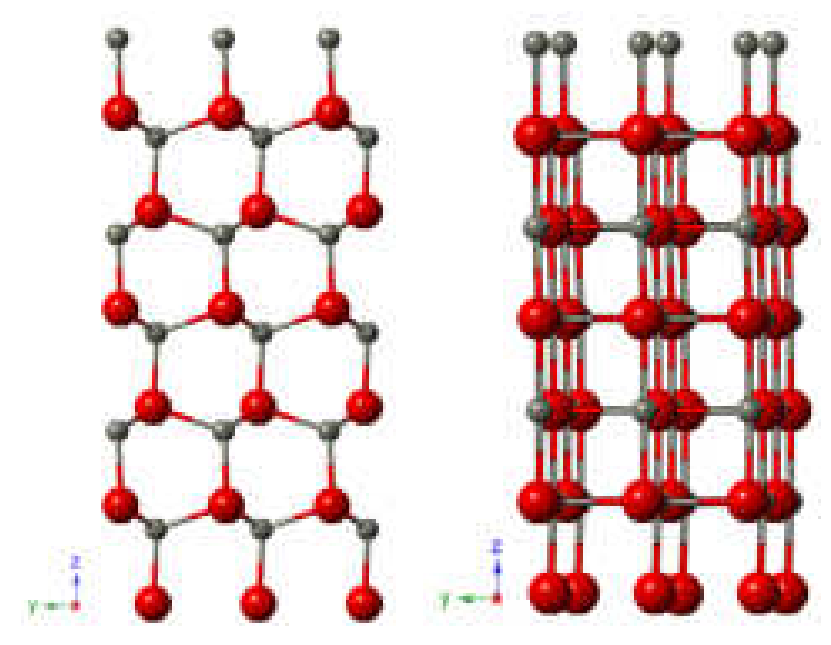

Şekil 1. ZnO’nun kristal yapıları: Sıfır basınçta P6 ${ }_{3} \mathrm{mc}$ fazı (sol) ve 30 GPa'da Fm $\overline{3} \mathrm{~m}$ fazı (să̆).

Sabit basınç MD simülasyonlarında tahmin edilen geçiş basınç değerleri (30 GPa) genelde deneysel sonuçlardan (ortalama $9 \mathrm{GPa}$ ) elde edilenlerden fazla çıkmaktadır. 
Bunun sebebi de, sistemlerin, bir fazdan bir başka faza geçerken dikkate değer bir enerji bariyeri ile karşı karşıya kalmalarından kaynaklanmaktadır. Simüle edilmiş sistemler faz geçişi elde edebilmek için bu enerji bariyerini geçmek isteyecektir. Bundan dolayı da fazlaca basınca maruz kalacaktır. Bundan dolayı bir sonraki aşama da, ZnO'nun yüksek basınç fazlarının kararlılığını çalışmak için enerji-hacim hesaplamalarını dikkate aldık. Hesaplanan toplam enerji-hacim ilişkileri eşitlik 1'de verilen 3. derece BirchMurnaghan [33, 34] durum denklemine uyduruldu ve Şekil 2'de gösterildi.

$$
P=1.5 B_{0}\left[\left(V / V_{0}\right)^{-7 / 3}-\left(V / V_{0}\right)^{-5 / 3}\right] x\left\{1+0.75\left(B_{0}^{\prime}-4\right)\left[\left(V / V_{0}\right)^{-2 / 3}-1\right]\right\}
$$

Burada $\mathrm{P}$, basınç, V, hacim, $\mathrm{V}_{0}, \mathrm{~B}_{0}$ ve $\mathrm{B}_{0}^{\prime}$ ise sıfır basınçta sırasıyla, hacim, bulk modülü ve bulk modülünün basınca göre türevidir.

Tablo 1. ZnO'nun B4 ve B1yapıları için geçiş basınç değerleri, örgü uzunlukları, hacim, bulk modülü ve bulk modülünün türev değerleri.

\begin{tabular}{ccccccccc}
\hline Fazlar & $\mathbf{P}_{\mathbf{T}}(\mathbf{G P a})$ & $\mathbf{a}(\AA)$ & $\mathbf{b}(\AA)$ & $\mathbf{c}(\AA)$ & $\mathbf{V}\left(\AA^{\mathbf{3}}\right)$ & $\mathbf{B}_{\mathbf{0}}(\mathbf{G P a})$ & $\mathbf{B}_{\mathbf{0}}^{\prime}$ & Kaynaklar \\
\hline $\mathbf{P 6}_{\mathbf{3}} \mathbf{m} \mathbf{c}$ & 0 & 3.2896 & 3.2896 & 5.2829 & 49.51 & 168.43 & 4.17 & Bu Çalışma \\
& & 3.1900 & 3.1900 & 5.1800 & 49.18 & 146.00 & & {$[35]$} \\
& & 3.2562 & 3.2562 & 5.2563 & & & & {$[7]$} \\
& & 3.1950 & 3.1950 & 5.1200 & & 161.60 & 4.53 & {$[9]$} \\
& & 3.2890 & 3.2890 & 5.3080 & & 128.20 & & {$[5]$} \\
& & 3.1841 & 3.1841 & 5.1550 & & 145.90 & 3.72 & {$[2]$} \\
& & 3.2077 & 3.2077 & 5.1636 & 46.00 & 168.40 & 4.34 & {$[1]$} \\
$\mathbf{F m} \overline{\mathbf{3}} \mathbf{m}$ & & 3.1832 & 3.1832 & 5.1482 & 45.16 & 164.36 & 3.77 & {$[6]$} \\
& 9.00 & 4.1746 & 4.1746 & 4.1746 & 72.75 & 201.84 & 4.49 & Bu Çalışma \\
& 9.00 & 4.2300 & 4.2300 & 4.2300 & 79.90 & 223.00 & & {$[35]$} \\
& 13.0 & 4.2120 & 4.2120 & 4.2120 & & & & {$[7]$} \\
& 9.48 & 4.2170 & 4.2170 & 4.2170 & & 208.00 & 4.80 & {$[9]$} \\
& 8.72 & 4.3390 & 4.3390 & 4.3390 & & 165.00 & & {$[5]$} \\
& 8.80 & 4.2110 & 4.2110 & 4.2110 & & 210.10 & 4.44 & {$[2]$} \\
& 8.08 & 4.2230 & 4.2230 & 4.2230 & 75.20 & 209.60 & 4.46 & {$[1]$} \\
& 10.49 & 4.2100 & 4.2100 & 4.2100 & 74.63 & 229.83 & 3.67 & {$[6]$} \\
\hline
\end{tabular}

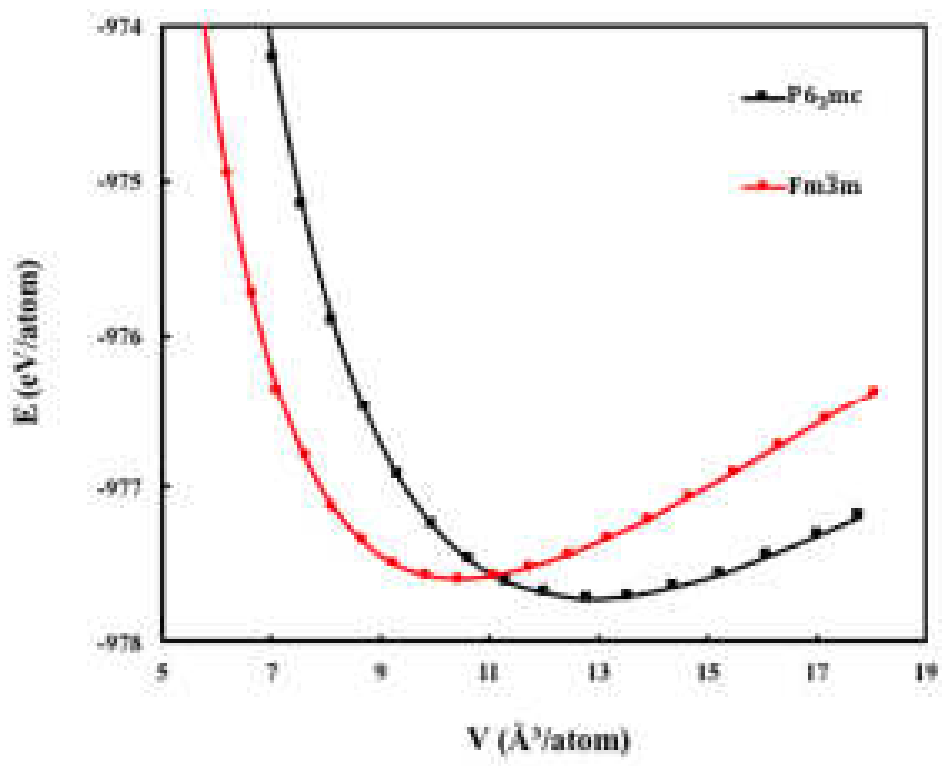

Şekil 2. ZnO bileşiğinin elde edilen kararlı fazlarının enerji-hacim grafiği. 
Verilen basınç ve sıcaklık değerinde en termodinamik kararlı fazın hangisi olduğuna karar vermek için Gibbs serbest enerjisini kullandık. Gibbs serbest enerjisi eşitlik 2' de verildiği gibidir.

$\mathrm{G}=\mathrm{E}_{\mathrm{tot}}+\mathrm{PV}-\mathrm{TS}$

Burada E, P, V ve S sırasıyla, toplam enerji, basınç, hacim ve entropidir. Yapmış olduğumuz teorik çalışmalar, $0 \mathrm{~K}$ sıcaklıkta başarıldı. Bu yüzden "TS" terimi ihmal edildi. Böylece, Gibbs serbest enerjisi G, eşitlik 3'de verilen entalpiye eşit oldu.

$\mathrm{H}=\mathrm{E}_{\mathrm{tot}}+\mathrm{PV}$

Burada $\mathrm{P}=-\partial \mathrm{E}_{\text {tot }} / \partial \mathrm{V}$. Entalpi hesaplamaları genellikle, deneysel sonuçlarla uyum halinde olan geçiş basıncı değerlerini verir. İki entalpi eğrisinin kesişimi, bu iki faz arasındaki basınç ihtiva eden faz geçişini gösterir. Geçiş basıncını belirleyebilmek için basıncın fonksiyonu olarak ZnO'nun elde edilen fazları için Şekil 3'de görüldügüu gibi entalpi eğrisini çizdik. Entalpi eğrisini çizerken enerji-hacim verilerini kullandık.

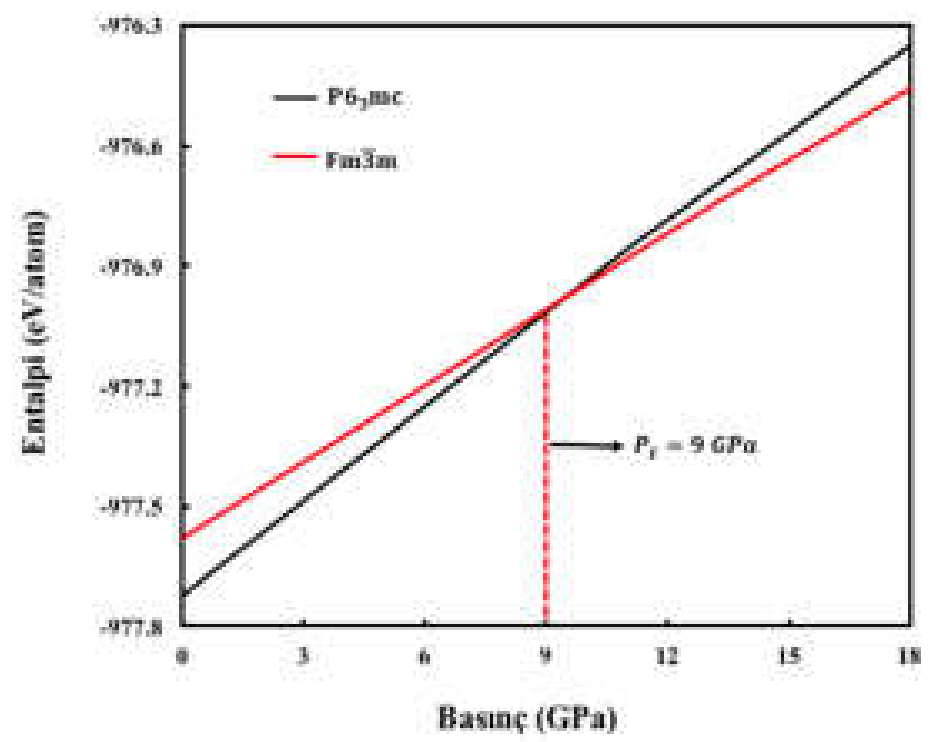

Şekil 3. Basıncın fonksiyonu olarak ZnO’nun kararlı fazları için entalpi grafiği.

Şekil 3'den de görüldüğü gibi ZnO'nun uzay grubu P63mc olan hekzagonal yapısı ile uzay grubu $\mathrm{Fm} \overline{3} \mathrm{~m}$ olan kübik yapısı arasında geçiş basıncı yaklaşık 9 GPa olarak elde edilmiştir. Tablo 1.'den de görüldüğü gibi deneysel ve diğer teorik çalışmalarla entalpi hesabı sonucu elde ettiğimiz geçiş basıncı değeri iyi uyum halindedir.

Faz geçişlerinin mekanizmasını açıklayabilmek için simulasyon hücresinin örgü öteleme vektörlerinin uzunlukları ve bu vektörler arasındaki açıların simülasyon adımlarına göre nasıl değiştikleri incelendi. Bu vektörler, sırasıyla [100], [010] ve [001] doğrultuları boyunca $\vec{A}, \vec{B}$ ve $\vec{C}$ ile gösterildi. $\vec{A}$ ile $\vec{B}$ vektörleri arasındaki açı $\gamma$, $\vec{A}$ ile $\vec{C}$ vektörleri arasındaki açı $\beta$ ve $\vec{B}$ ile $\vec{C}$ vektörleri arasındaki açı $\alpha$ ile ifade edildi. Örgü vektörlerinin uzunlukları ve bu vektörler arasındaki açılarının simulasyon adımlarına göre değişimi, Şekil 4'de $30 \mathrm{GPa}$ için gösterildi. 

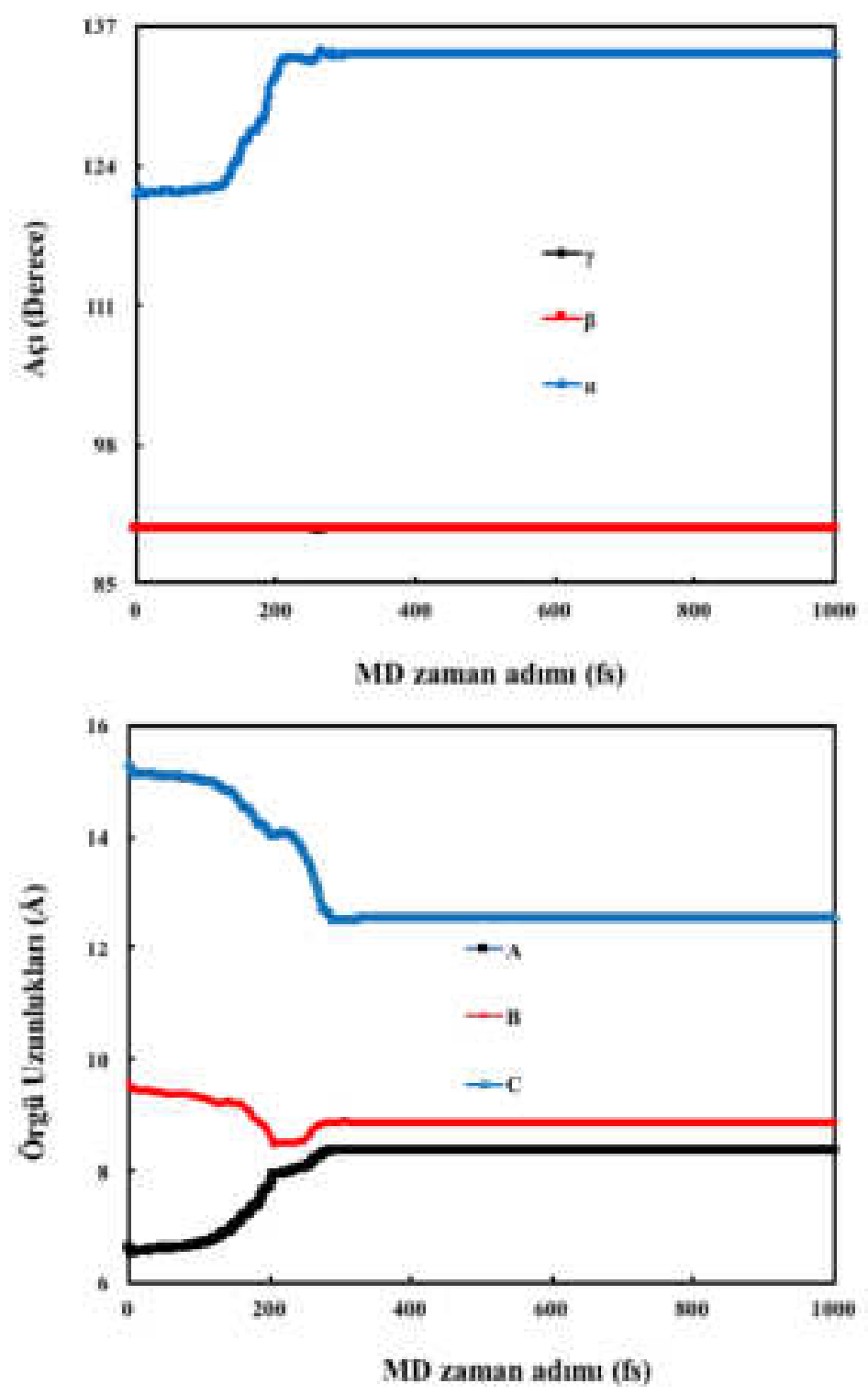

Şekil 4. ZnO’nun 30 GPa'da örgü vektörü uzunlukları ve bu vektörler arasındaki açıların her bir MD zaman adımına göre değişsimi grafiği.

Şekil 4'den görüldüğü gibi, $\gamma$ ve $\beta$ açılarında herhangi bir değişim söz konusu olmamışken $\alpha$ açısında yaklaşık 250 fs'ye ye kadar dikkate değer bir değişim olmuş böylece yaklaşık 136 fs'ye ye kadar artmıştır. Sonrasında ise simulasyon boyunca sabit kalmıştır. Örgü uzunluklarında ise A, B ve C değerleri yaklaşık 250 fs'ye ye kadar değişmiş sonrasında ise simulasyon boyunca sabit kalmıştır. Açı ve uzunluktaki bu değişimler bize faz dönüşümünün gerçekleştiğinin ispatı niteliğindedir.

ZnO'da B4 $\rightarrow$ B1 faz geçişinin termodinamik doğasını belirleyebilmek için Şekil 5'de basınç-hacim ve basınç-örgü sabitleri ilişkilerini çizdik. 30 GPa'da B1 tipi yap1 karakterize edilir. $\mathrm{Bu}$ bulgu, B4 yapıdan B1 tipi bir yapıya birinci derece faz dönüşümünün $20 \mathrm{GPa}$ ve $30 \mathrm{GPa}$ arasında olduğunu göstermektedir. Sonrasında B1 yapısının uygulanan basınca nasıl tepki vereceğini görebilmek için basınç değerini $100 \mathrm{GPa}$ ya kadar arttırdık ancak başka faz dönüşümüne rastlayamadık. 

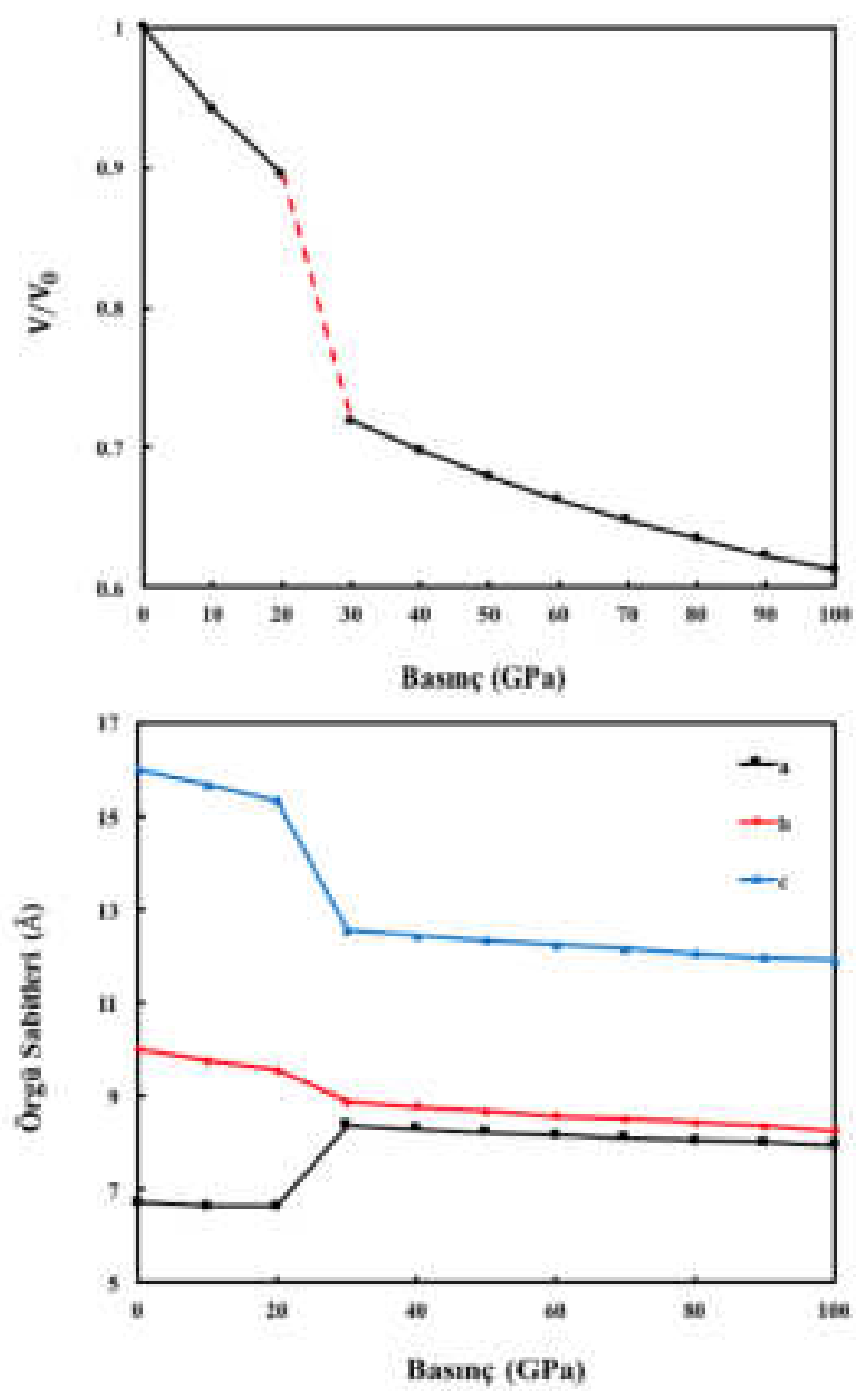

Şekil 5. Basıncın fonksiyonu olarak simülasyon hücre hacminin ve örgü sabitlerinin değişimi grafiği.

Şekil 5'den de görüldüğü gibi hacim ve örgü sabitleri, basınç değeri 20 GPa'dan 30 GPa'ya artırıldığında belirgin bir şekilde değişmiştir. Bu değişimin sebebi $30 \mathrm{GPa}$ 'da malzemenin P6 ${ }_{3} \mathrm{mc}$ fazının $\mathrm{Fm} \overline{3} \mathrm{~m}$ fazına dönüşmesinden dolayıdır. Bu dönüşüm sırasında hacim değerinde meydana gelen büyük çöküş ise bize faz geçişinin birinci dereceden olduğunu göstermektedir.

$30 \mathrm{GPa}$ 'da elde edilen bu faz değişimi esnasında herhangi bir ara durum olup olmadığ tespit edebilmek için B1 yapısının her bir minimizasyon adımı detaylı olarak KPLOT programı ile analiz edilmiştir. Analiz sonucunda, ZnO'nun P6 3 mc fazı 110. adımda, uzay grubu Cmc2 ${ }_{1}$ olan ortorombik bir yapıya ve sonrasinda 290. adımda uzay grubu Fm $\overline{3} \mathrm{~m}$ olan kübik yapıya dönmüştür. Elde edilen bu ortorombik yapının örgü sabitleri $a=3.3577, b=5.2531, c=5.0043$ dir. Şekil 6' da kübik yapının oluşumu görülmektedir. 


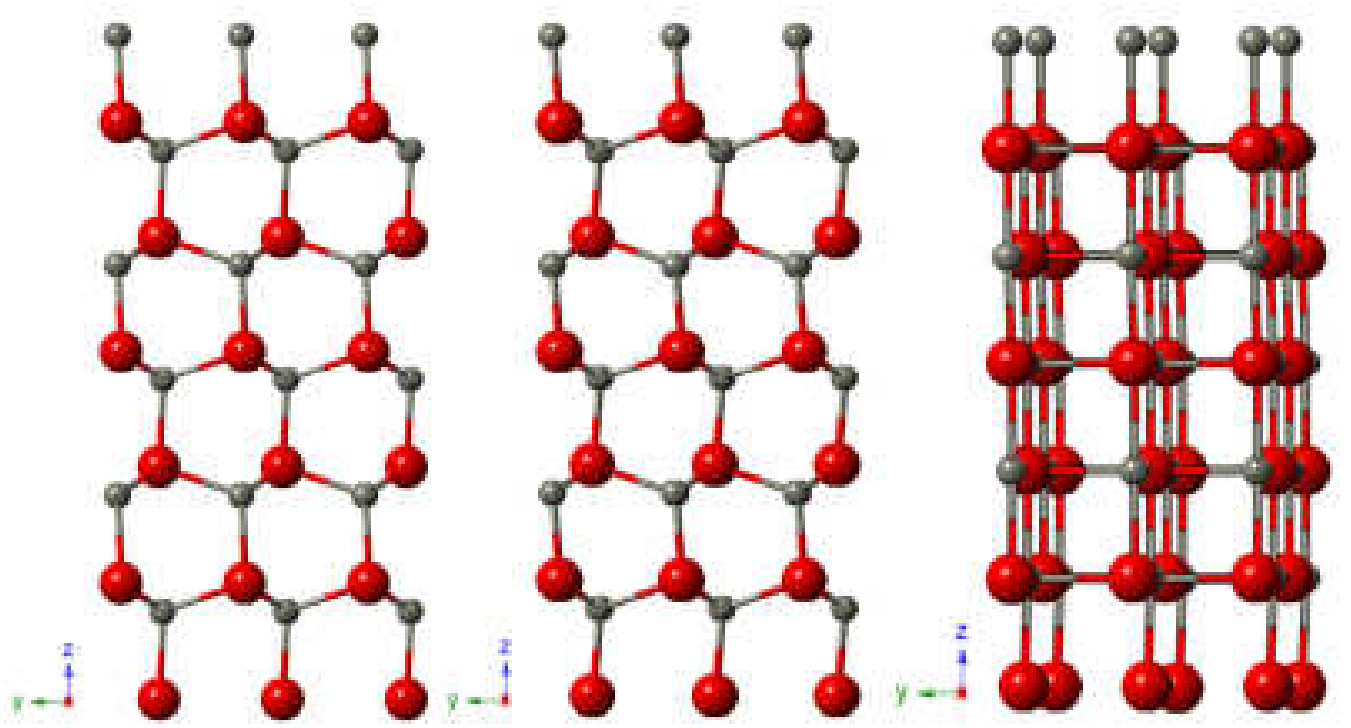

Şekil 6. 30 GPa' da kübik yapının oluşumu.

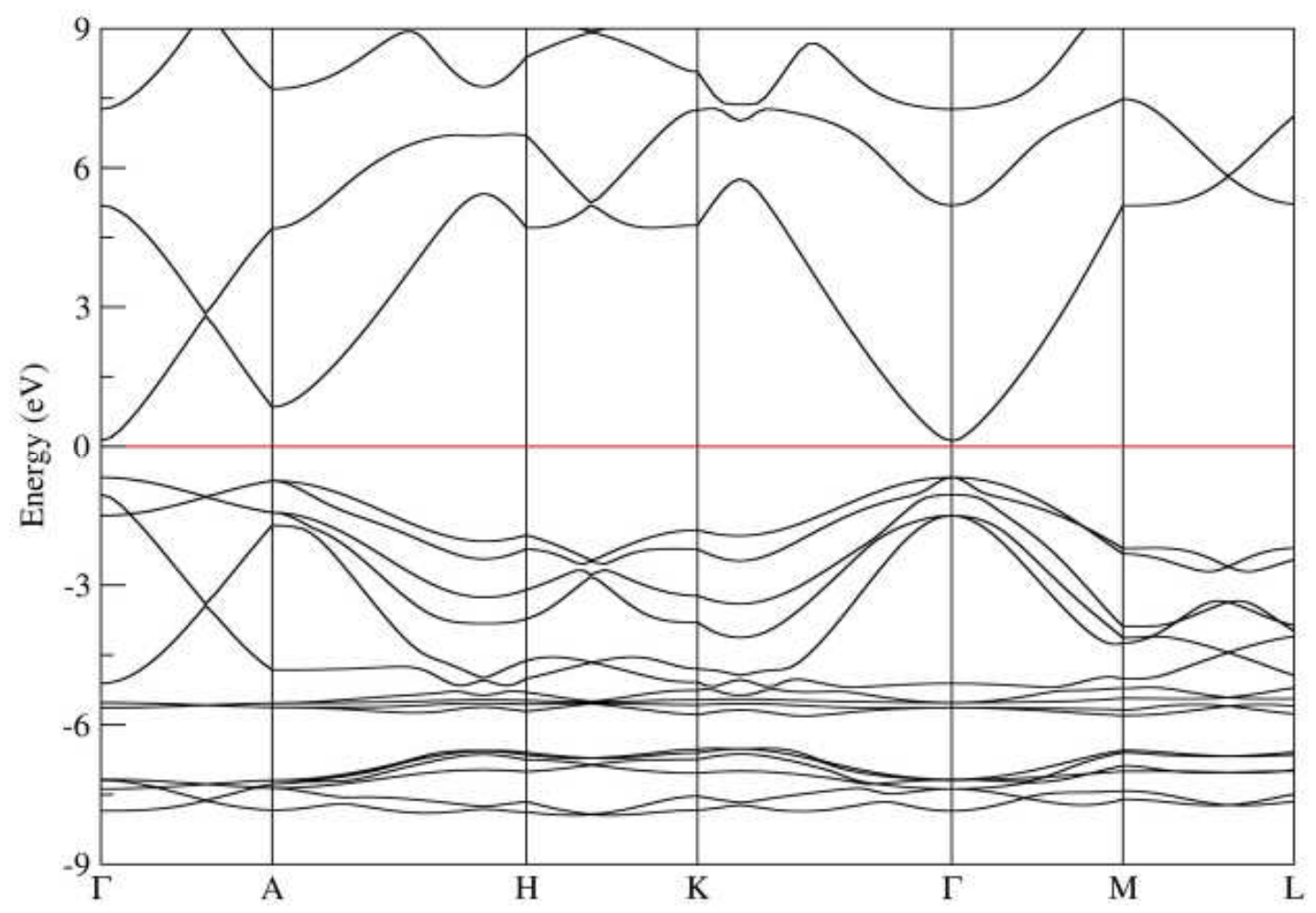

Şekil 7. ZnO’nun B4 yapısı için hesaplanan elektronik bant yapısı eğrisi.

B4 ve B1yapıları için hesaplanan elektronik bant yapısı eğrileri sırası ile Şekil 7 ve Şekil 8'de yüksek simetri yönleri boyunca verildi ve enerjinin bir fonksiyonu olarak gösterildi. Fermi enerjisi seviyesi $0 \mathrm{eV}$ olarak ayarlandı. Simetri noktaları B4 fazı için $\Gamma-\mathrm{M}-\mathrm{K}-\Gamma-\mathrm{A}-\mathrm{L}-\mathrm{H}$ ve $\mathrm{B} 1$ fazı için $\Gamma-\mathrm{X}-\mathrm{W}-\Gamma-\mathrm{L}-\mathrm{W}-\mathrm{L}-\mathrm{X}$ olarak seçildi. Elektronik bant yapısı grafiklerinden görüldüğü gibi valans band1, Fermi Enerjisi seviyesinin altına, iletim bandı ise üstüne yerleşmiştir. Sonuçlarımız, ZnO'nun $0 \mathrm{GPa}$ 'da yaklaşık 0.70 eV'lik [1, 2, 5, 9, 11, 35] bir bant aralığı ile doğrudan bant geçişine karşılık geldiğini göstermektedir. Çünkü valans bandının maksimumu ve iletim bandının 
minimumu aynı simetri noktasındadır $[\Gamma]$. $30 \mathrm{GPa}$ 'da ise ZnO'nun B1 fazının, 1.99 eV'lik [1, 2, 5, 9, 11, 35] bir bant aralığı ile dolaylı bant geçişine karşılık geldiği görülmektedir. Elde edilen sonuçlara göre ZnO'nun her iki fazı için de valans bandı ile iletim bandı arasında bir bant aralığı mevcuttur ki bu iki yapının da yarıiletken özellik gösterdiği anlamına gelir.

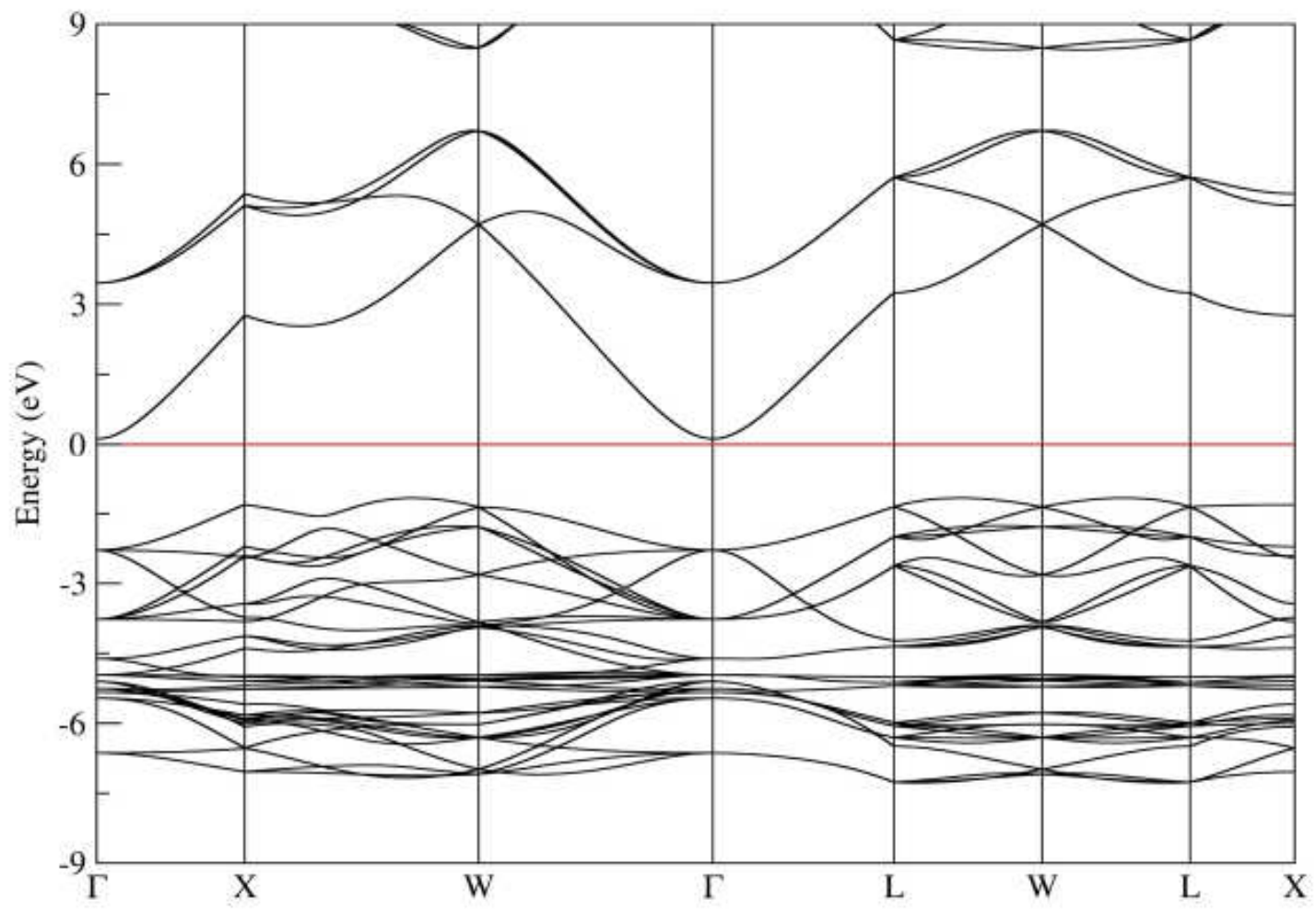

Şekil 8. ZnO’nun B1 yapısı için hesaplanan elektronik bant yapısı eğrisi.

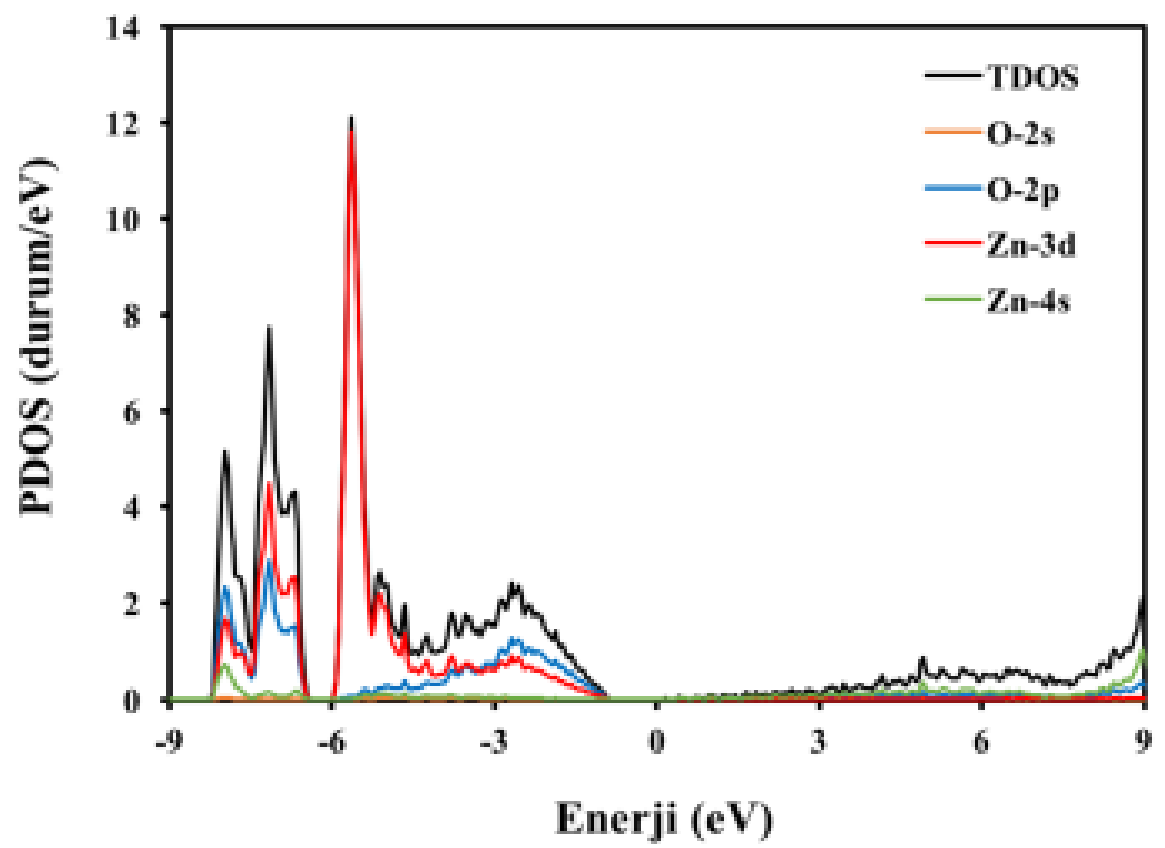

Şekil 9. ZnO’nun B4 yapısı için hesaplanan kısmi durum yoğunluğu grafiği. 
ZnO'nun elektronik doğası hakkında daha fazla bilgi elde etmek için kısmi durum yoğunluğunu (PDOS) hesapladık. Şekil 9 ve Şekil 10'den görüldüğü gibi ZnO'nun elde edilen her iki kararlı fazı için de en büyük katkının 0 - (-9) aralığında Zn-3d ve 0 - (+9) aralığında $\mathrm{Zn}-4 \mathrm{~s}$ den geldiği görülmüştür.

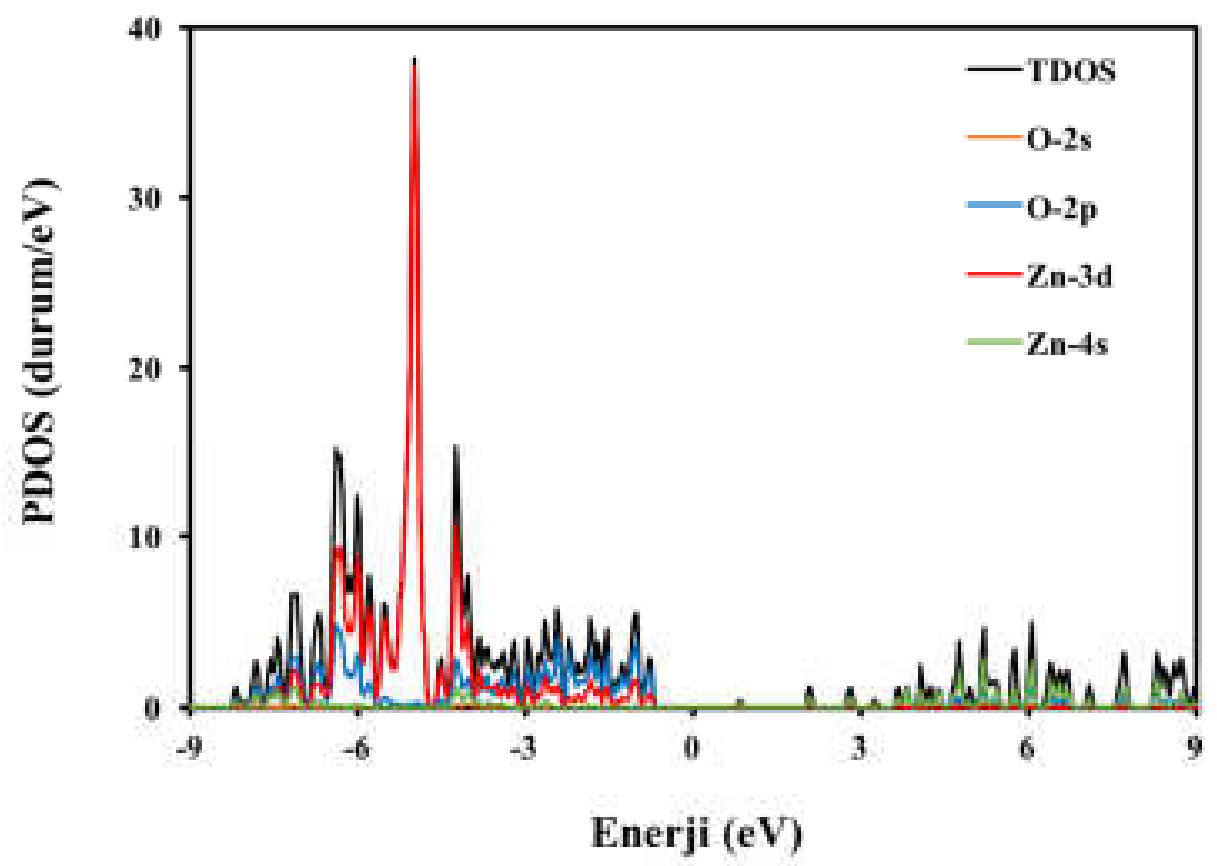

Şekil 10. ZnO’nun B1 yapısı için hesaplanan kısmi durum yoğunluğu grafiği.

\section{Sonuç}

Özetle, sıfır sıcaklıkta 0 ile $100 \mathrm{GPa}$ arasında değişen yüksek hidrostatik basınç altında ZnO'nun yapısal ve elektronik özellikleri moleküler dinamik simülasyonları kullanılarak incelenmiştir. Faz geçiş mekanizmasını $\mathrm{P}_{3} \mathrm{mc} \rightarrow \mathrm{Fm} \overline{3} \mathrm{~m}$ olarak elde ettik. Yapılan detaylı analizler sonucunda $\mathrm{P}_{3} \mathrm{mc} \rightarrow \mathrm{Fm} \overline{3} \mathrm{~m}$ faz geçişi esnasında uzay grubu $\mathrm{Cmc} 2{ }_{1}$ olan ortorombik bir ara durum elde edildi. Bu ara durum yaptığımız literatür çalışmaları sonucunda ilk defa bu çalışmada görülmüştür. Ayrıca, ZnO'nun elektronik özelliklerini inceledik ve $\mathrm{P}_{3} \mathrm{mc}$ ve $\mathrm{Fm} \overline{3} \mathrm{~m}$ fazları için bant aralıklarını sırasıyla yaklaşık olarak $0.70 \mathrm{eV}$ ve $1.99 \mathrm{eV}$ olarak elde ettik.

\section{Kaynaklar}

[1] Amrani, B., Chiboub, I., Hiadsi, S., Benmessabih, T. ve Hamdadou, N., Structural and electronic properties of $\mathrm{ZnO}$ under high pressures, Solid State Communications, 137, 7, 395-399, (2006).

[2] Cui, S., Feng, W., Hu, H., Feng, Z. ve Wang, Y., Structural and electronic properties of $\mathrm{ZnO}$ under high pressure, Journal of Alloys and Compounds, 476, 1, 306-310, (2009).

[3] Desgreniers, S., High-density phases of $\mathrm{ZnO}$ : Structural and compressive parameters, Physical Review B, 58, 21, 14102, (1998). 
[4] Dong, X., Liu, F., Xie, Y., Shi, W., Ye, X. ve Jiang, J., Pressure-induced structural transition of $\mathrm{ZnO}$ nanocrystals studied with molecular dynamics, Computational Materials Science, 65, 450-455, (2012).

[5] Kuang, F.G., Kuang, X.Y., Kang, S.Y., Zhong, M.M. ve Mao, A.J., A first principle study of pressure-induced effects on phase transitions, band structures and elasticity of zinc oxide, Materials Science in Semiconductor Processing, 23, 63-71, (2014).

[6] Maouche, D., Saoud, F.S. ve Louail, L., Dependence of structural properties of $\mathrm{ZnO}$ on high pressure, Materials Chemistry and Physics, 106, 1, 11-15, (2007).

[7] $\mathrm{Pu}, \mathrm{C}$., Tang, X. ve Zhang, Q., First principles study on the structural and optical properties of the high-pressure $\mathrm{ZnO}$ phases, Solid State Communications, 151, 21, 1533-1536, (2011).

[8] Recio, J., Blanco, M., Luana, V., Pandey, R., Gerward, L. ve Olsen, J.S., Compressibility of the high-pressure rocksalt phase of ZnO, Physical Review B, 58, 14, 8949, (1998).

[9] Saeed, Y., Shaukat, A., Ikram, N. ve Tanveer, M., Structural and electronic properties of rock salt phase of $\mathrm{ZnO}$ under compression, Journal of Physics and Chemistry of Solids, 69, 7, 1676-1683, (2008).

[10] Saoud, F.S., Plenet, J.C. ve Henini, M., Band gap and partial density of states for ZnO: Under high pressure, Journal of Alloys and Compounds, 619, 812-819, (2015).

[11] Schleife, A., Fuchs, F., Furthmüller, J. ve Bechstedt, F., First-principles study of ground-and excited-state properties of $\mathrm{MgO}, \mathrm{ZnO}$, and $\mathrm{CdO}$ polymorphs, Physical Review B, 73, 24, 245212, (2006).

[12] Usuda, M., Hamada, N., Kotani, T. ve van Schilfgaarde, M., All-electron GW calculation based on the LAPW method: Application to wurtzite $\mathrm{ZnO}$, Physical Review B, 66, 12, 125101, (2002).

[13] Xin-Yu, Z., Zhou-Wen, C., Yan-Peng, Q., Yan, F., Liang, Z., Li, Q., MingZhen, M., Ri-Ping, L. ve Wen-Kui, W., Ab initio comparative study of zincblende and wurtzite $\mathrm{ZnO}$, Chinese Physics Letters, 24, 4, 1032, (2007).

[14] Stolt, L., Hedström, J., Kessler, J., Ruckh, M., Velthaus, K.O. ve Schock, H.W., $\mathrm{ZnO} / \mathrm{CdS} / \mathrm{CuInSe} 2$ thin-film solar cells with improved performance, Applied Physics Letters, 62, 6, 597-599, (1993).

[15] Ikeda, T., Sato, K., Hayashi, Y., Wakayama, Y., Adachi, K. ve Nishimura, H., Surface microstructures of $\mathrm{ZnO}$ coated $\mathrm{SnO} 2$ : F films, Solar Energy Materials and Solar Cells, 34, 1-4, 379-384, (1994).

[16] Karzel, H., Potzel, W., Köfferlein, M., Schiessl, W., Steiner, M., Hiller, U., Kalvius, G.M., Mitchell, D.W., Das, T.P., Blaha, P., Schwarz, K. ve Pasternak, M.P., Lattice dynamics and hyperfine interactions in $\mathrm{ZnO}$ and $\mathrm{ZnSe}$ at high external pressures, Physical Review B, 53, 17, 11425, (1996).

[17] Jaffe, J. ve Hess, A., Hartree-Fock study of phase changes in $\mathrm{ZnO}$ at high pressure, Physical Review B, 48, 11, 7903, (1993).

[18] Jaffe, J.E., Snyder, J.A., Lin, Z. ve Hess, A.C., LDA and GGA calculations for high-pressure phase transitions in $\mathrm{ZnO}$ and $\mathrm{MgO}$, Physical Review B, 62, 3, 1660, (2000).

[19] Bates, C.H., White, W.B. ve Roy, R., New high-pressure polymorph of zinc oxide, Science, 137, 3534, 993-993, (1962).

[20] Jamieson, J.C., The phase behavior of simple compounds, Physics of the Earth and Planetary Interiors, 3, 201-203, (1970). 
[21] Yu, S., Spain, I. ve Skelton, E., High pressure phase transitions in tetrahedrally coordinated semiconducting compounds, Solid State Communications, 25, 1, 49-52, (1978).

[22] Decremps, F., Zhang, J., Li, B. ve Liebermann, R.C., Pressure-induced softening of shear modes in ZnO, Physical Review B, 63, 22, 224105, (2001).

[23] Decremps, F., Zhang, J. ve Liebermann, R., New phase boundary and highpressure thermoelasticity of $\mathrm{ZnO}$, EPL (Europhysics Letters), 51, 3, 268, (2000).

[24] Ahuja, R., Fast, L., Eriksson, O., Wills, J. ve Johansson, B., Elastic and high pressure properties of ZnO, Journal of Applied Physics, 83, 12, 8065-8067, (1998).

[25] Saib, S. ve Bouarissa, N., Structural parameters and transition pressures of ZnO: ab-initio calculations, Physica Status Solidi (b), 244, 3, 1063-1069, (2007).

[26] Ordejón, P., Artacho, E. ve Soler, J.M., Self-consistent order-N densityfunctional calculations for very large systems, Physical Review B, 53, 16, R10441, (1996).

[27] Perdew, J.P., Burke, K. ve Ernzerhof, M., Generalized gradient approximation made simple, Physical Review Letters, 77, 18, 3865, (1996).

[28] Troullier, N. ve Martins, J.L., Efficient pseudopotentials for plane-wave calculations, Physical Review B, 43, 3, 1993, (1991).

[29] Monkhorst, H.J. ve Pack, J.D., Special points for Brillouin-zone integrations, Physical Review B, 13, 12, 5188, (1976).

[30] Parrinello, M. ve Rahman, A., Crystal structure and pair potentials: A molecular-dynamics study, Physical Review Letters, 45, 14, 1196, (1980).

[31] Hundt, R., SchoÈn, J.C., Hannemann, A. ve Jansen, M., Determination of symmetries and idealized cell parameters for simulated structures, Journal of Applied Crystallography, 32, 3, 413-416, (1999).

[32] Hannemann, A., Hundt, R., Schön, J. ve Jansen, M., A new algorithm for spacegroup determination, Journal of Applied Crystallography, 31, 6, 922-928, (1998).

[33] Birch, F., Finite elastic strain of cubic crystals, Physical Review, 71, 11, 809, (1947).

[34] Murnaghan, F., The compressibility of media under extreme pressures, Proceedings of the National Academy of Sciences, 30, 9, 244-247, (1944).

[35] Zagorac, D., Schön, J., Zagorac, J. ve Jansen, M., Prediction of structure candidates for zinc oxide as a function of pressure and investigation of their electronic properties, Physical Review B, 89, 7, 075201, (2014). 